\title{
Study on Dye Wastewater Degradation by Fenton Reaction under Thermal-assistance
}

\author{
Jingwen Ran ${ }^{1,2, a}$, Shuibin Yang ${ }^{1,2, b^{*}}$ \\ ${ }^{1}$ Chemical Engineering College, Huanggang Normal University, Huanggang, China \\ ${ }^{2}$ Hubei Key Laboratory for Processing and Application of Catalytic Materials, China \\ aemail: ranjw@126.com; ${ }^{b}$ email: yangsbcg@126.com
}

\begin{abstract}
Keywords: Fenton reaction; Thermal-assistance; Dye wastewater; Condition optimization; Removal of COD
\end{abstract}

Abstract. The Fenton reaction under thermal-assistance was applied to the removal of chemical oxygen demand using chromate (COD) and color from dye wastewater in which initial COD was $5600-13000 \mathrm{mg} / \mathrm{L}$. The reaction temperature and time were $50^{\circ} \mathrm{C}$ and $30 \mathrm{~min}$. The initial concentrations of $\mathrm{H}_{2} \mathrm{O}_{2}$ and $\mathrm{Fe}^{2+}$ were $6 \mathrm{~g} / \mathrm{L}$ and $0.4 \mathrm{~g} / \mathrm{L}$. The removal ratios of fluorescent Red FB, clear Blue RR and clear Green 5B were 77.2, 93.5 and $86.8 \%$, respectively.

\section{Introduction}

The free release of dye wastewater of high-strength of COD increases the environmental pollution and the health risks because of dye compounds containing toxic benzene or naphtha rings. Different methods have been developed for dye removal, including chemical precipitation, chemical oxidation, adsorption, biological treatment and membrane-based techniques[1-7]. In recent years, the Fenton reaction formed the well-known chemical advanced oxidation process. The method is cost-effective with relatively low-strength wastewater[8-12]. However, the rate of Fenton reaction under photo-assistance was slow in room temperature when the COD was high and could not meet the production needs, especially for some difficult degraded compounds such as dyestuff. Therefore, purpose of this study was to apply the Fenton method under thermal-assistance to high-strength dye wastewater. We investigated the $\mathrm{H}_{2} \mathrm{O}_{2}$ and $\mathrm{Fe}^{2+}$ dosage, reaction temperature and time and the degraded rate.

\section{Materials and methods}

The dye wastewater used was supplied by the Dyestuff Company, Yanchen city, China. They came from production workshops of fluorescent red FB, clear blue RR and clear green 5B. Table 1 shows the characteristics of used wastewater.

Table 1 Characteristics of dye wastewater

\begin{tabular}{lll}
\hline Items & COD $(\mathrm{mg} / \mathrm{L})$ & $\mathrm{pH}$ \\
\hline Red FB & 13500 & -0.3 \\
Blue RR & 5680 & 6.7 \\
Green 5B & 13066 & 0.37 \\
\hline
\end{tabular}

The Fenton method was applied in $200 \mathrm{~mL}$ flasks containing $100 \mathrm{~mL}$ dye wastewater (adjust the $\mathrm{pH}=3$ with $\mathrm{H}_{2} \mathrm{SO}_{4}$ or $\mathrm{NaOH}$ ), $2 \mathrm{mLH}_{2} \mathrm{O}_{2}(30 \%)$ and $0.2 \mathrm{~g} \mathrm{FeSO}_{4} \cdot 7 \mathrm{H}_{2} \mathrm{O}$. The flask was then allowed to stand without stirring for $30 \mathrm{~min}$ at $50^{\circ} \mathrm{C}$ water bath. After that, $2 \mathrm{~g}$ of $\mathrm{MnO}_{2}$ was added to the flask and the mixture was vigorously stirred to decompose the extra $\mathrm{H}_{2} \mathrm{O}_{2}$ quickly for 2 hours. At last, the $\mathrm{pH}$ was neutralized to 10 with saturated $\mathrm{NaOH}$ solution and the precipitation was filtered and the clear liquid was used for COD determination.

The COD was measured by a closed reflux titrimetric method according to standard method [13]. The $\mathrm{H}_{2} \mathrm{O}_{2}$ concentration was determined using a standard iodometric method with potassium iodide and $\mathrm{Na}_{2} \mathrm{~S}_{2} \mathrm{O}_{3}$ solution as reactants [14]. The $\mathrm{pH}$ values were measured with a $\mathrm{pH}$ meter (Aoke 
company, China). The electron spin resonance (ESR) spectra were determined in the Chemistry Institute of the Chinese Academy of Sciences. The reagents used were of analytical grade and were from Sinopharm Chemical Reagent Co., Ltd.

\section{Result and Discussion}

Effect of reaction temperature

The degradation rates of clear Blue RR (initial COD $5680 \mathrm{mg} / \mathrm{L}$ ) and Green 5B (initial COD $13066 \mathrm{mg} / \mathrm{L}$ ) were evaluated under the conditions of $\mathrm{H}_{2} \mathrm{O}_{2} 6 \mathrm{~g} / \mathrm{L}$ and $\mathrm{Fe}^{2+} 0.4 \mathrm{~g} / \mathrm{L}$ and $\mathrm{pH}=3$ with different temperature for $30 \mathrm{~min}$ (see Fig. 1). The COD removal efficiencies in the Fenton process increased when the temperature was increased. The COD value was decreased slowly between 20 and $30^{\circ} \mathrm{Cand}$ the COD removal rates were about $35 \%$ and $26 \%$ in $30 \mathrm{~min}$. However, the removal rates increased obviously between 30 and $50^{\circ} \mathrm{C}$ and exceeded $93 \%$ and $86 \%$ in 30 min, respectively. With the temperature rising, the changes were slow gradually. According to these analytical results, the removal efficiencies for COD of dyes were high under proper thermal-assistance. In order to save energy, we chose $50^{\circ} \mathrm{C}$ in following experiment.

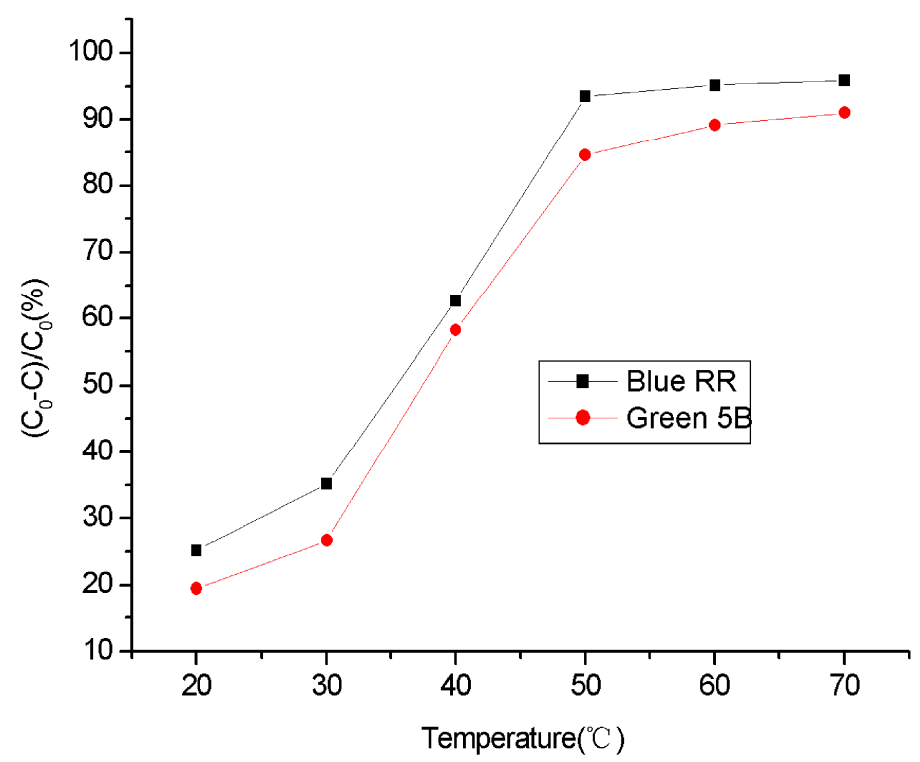

Fig. 1 Effect of different temperature on Blue RR and Green 5B

Effect of $\mathrm{Fe}^{2+}$ and $\mathrm{H}_{2} \mathrm{O}_{2}$ concentrations and $\mathrm{pH}$ values

It is important to optimize the amount of $\mathrm{H}_{2} \mathrm{O}_{2}$ in the Fenton process because the main cost of the method is the cost of $\mathrm{H}_{2} \mathrm{O}_{2}$. In addition, residual $\mathrm{H}_{2} \mathrm{O}_{2}$ in the effluent increases COD concentration of wastewater and disturbs the exact determination of COD. At the same time, the solution $\mathrm{pH}$ is a critical operating parameter affecting dyes removal efficiency in Fenton process because a change in $\mathrm{pH}$ of the solution will affects directly the mechanism of oxidation dyes. In order to find out their crossed influence, orthogonal experimental design was used to optimize the conditions. Based on our preliminary experimental studies, we chose three factors $\left(\mathrm{Fe}^{2+}\right.$ and $\mathrm{H}_{2} \mathrm{O}_{2}$ concentrations and $\mathrm{pH}$ values) and three levels to test at $50^{\circ} \mathrm{C}$ using $\mathrm{L}_{9}\left(3^{4}\right)$. The corresponding levels values are in table 2. The test results are shown in table 3. During experiments, the dye wastewater of clear Blue RR was used to monitor the change of COD.

Table 2 Header of orthogonal experimental design

\begin{tabular}{cccc}
\hline Level \Factor & $\mathrm{H}_{2} \mathrm{O}_{2}(\mathrm{~g} / \mathrm{L})$ & $\mathrm{Fe}^{2+}(\mathrm{g} / \mathrm{L})$ & $\mathrm{pH}$ \\
\hline 1 & 3 & 0.2 & 2 \\
2 & 6 & 0.4 & 3 \\
3 & 9 & 0.6 & 4 \\
\hline
\end{tabular}


During further orthogonal range analysis, $\mathrm{K} / 3$ stands for mean value at the same levels and extreme difference is used to estimate the influencing factors. From the table 3, concentration of $\mathrm{H}_{2} \mathrm{O}_{2}$ is critical because of the largest extreme difference. The concentration of $\mathrm{Fe}^{2+}$ is secondary and the $\mathrm{pH}$ values are not of importance if they are below 4. Overall consideration, the optimal values of different factors are $6 \mathrm{~g} / \mathrm{L}$ of $\mathrm{H}_{2} \mathrm{O}_{2}, 0.4 \mathrm{~g} / \mathrm{L}$ of $\mathrm{Fe}^{2+}$ and $\mathrm{pH}=3$.

Table 3 Range analysis of experimental data

\begin{tabular}{cccccc}
\hline Project & $\mathrm{H}_{2} \mathrm{O}_{2}(\mathrm{~g} / \mathrm{L})$ & $\mathrm{Fe}^{2+}(\mathrm{g} / \mathrm{L})$ & $\mathrm{pH}$ & $\mathrm{COD}(\mathrm{mg} / \mathrm{L})$ & $\left(\mathrm{C}_{0}-\mathrm{C}\right) / \mathrm{C}_{0}(\%)$ \\
\hline 1 & 3 & 0.2 & 2 & 2862.7 & 49.6 \\
2 & 3 & 0.4 & 3 & 2135.7 & 62.4 \\
3 & 3 & 0.6 & 4 & 2504.9 & 55.9 \\
4 & 6 & 0.2 & 3 & 806.6 & 85.8 \\
5 & 6 & 0.4 & 4 & 732.7 & 87.1 \\
6 & 6 & 0.6 & 2 & 508.3 & 91.0 \\
7 & 9 & 0.2 & 4 & 1502.1 & 73.6 \\
8 & 9 & 0.4 & 2 & 1483.5 & 91.3 \\
9 & 9 & 0.6 & 3 & 482.9 & 93.5 \\
$\mathrm{~K}_{1} / 3$ & 56.0 & 69.7 & 77.3 & & \\
$\mathrm{~K}_{2} / 3$ & 88.0 & 80.3 & 73.9 & & \\
$\mathrm{~K}_{3} / 3$ & 86.1 & 80.1 & 72.2 & & \\
Extreme & 32 & 10.6 & 5.1 & & \\
difference & & & & & \\
Best & 6 & 0.4 & 3 & & \\
project & & & & & \\
\hline
\end{tabular}

The optimal values of different factors were used to determine the COD removal of dye wastewater. The results are shown in Fig. 2. The three sorts of dye wastewater were degraded efficiently at $50^{\circ} \mathrm{C}$ for $30 \mathrm{~min}$. The degradation rates were fast at first and became slow gradually. Blue RR are degraded the easiest than Green 5B and Red 5B. It is the difference of their structures and concentrations to cause the change.

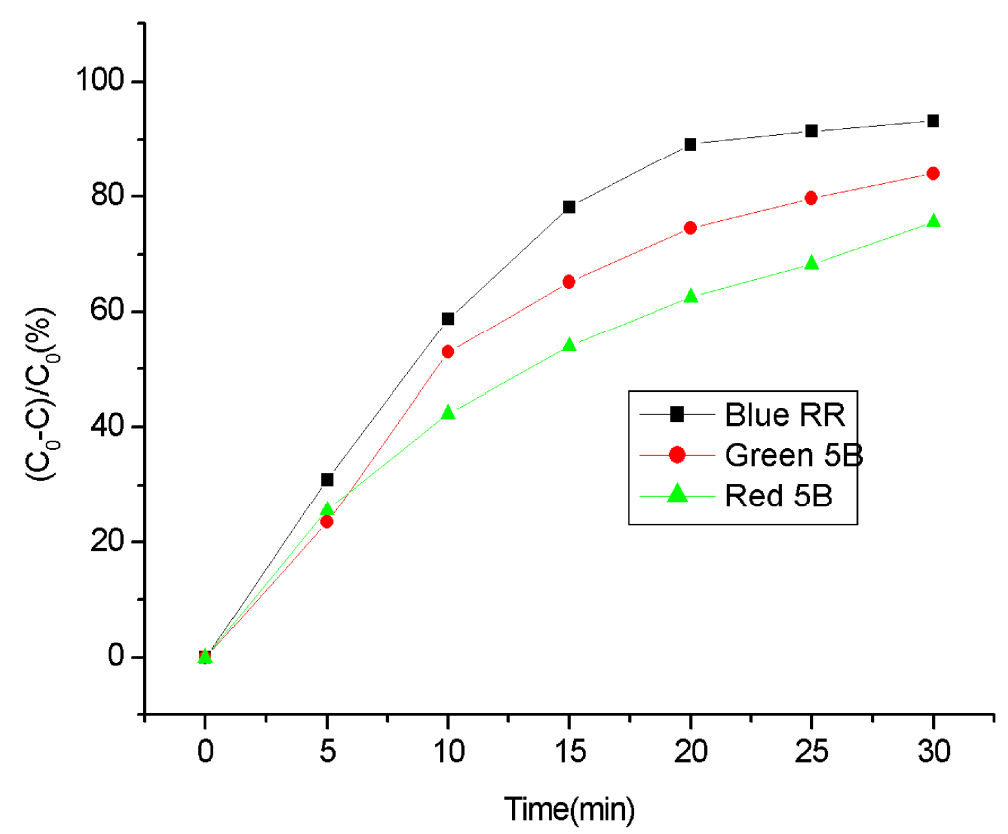

Fig. 2 The change of COD removal rates with the reaction time 
Mechanism analysis of thermal-assisted Fenton reaction

ESR technique $[15,16]$ was used to gain insight into the nature of the short-lived radicals formed during Fenton reaction. The results are displayed in Fig. 3. It was found that the signal of 5, 5-Dimethyl-1-pyrroline-N-oxide (DMPO) $\cdot \mathrm{OH}$ adducts characterized by an intensity ratio of 1:2:2:1 was observed in the reaction. The change of the intensity of four peaks of DMPO $\cdot \mathrm{OH}$ was small in room temperature, but the intensity was significantly enhanced with increasing temperature. It showed thermal-assistance could accelerate the generation of more $\cdot \mathrm{OH}$ radicals and help degrade the dye wastewater. The thermal decomposition of dye wastewater was secondary.

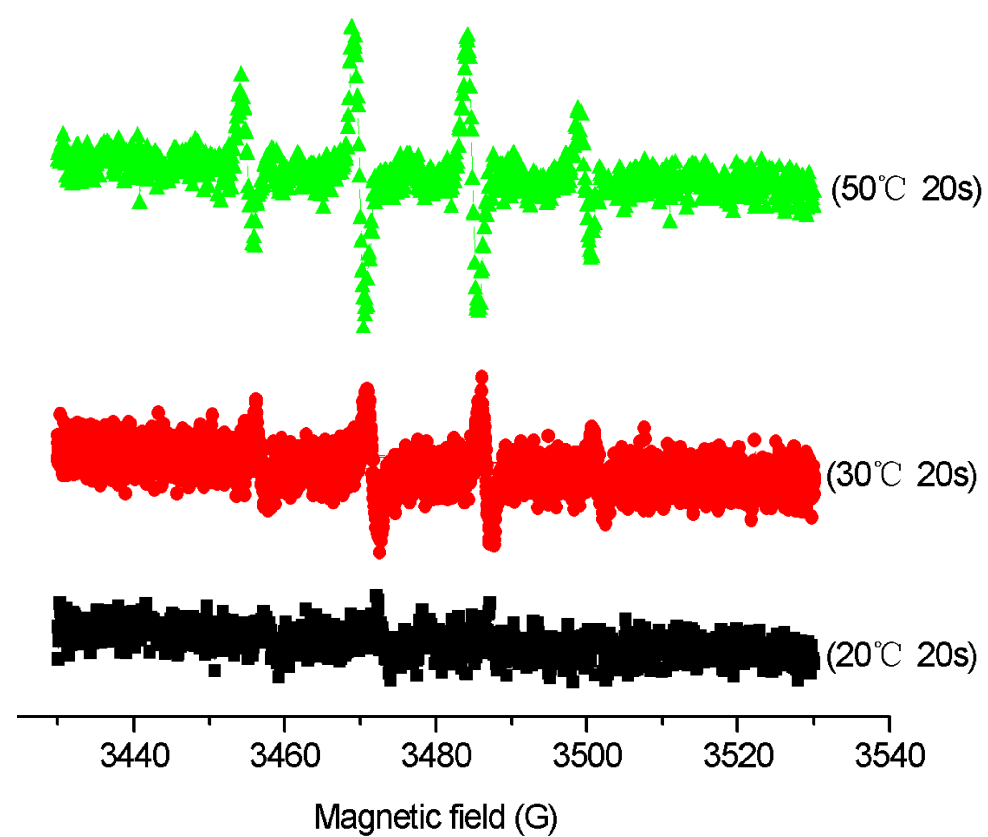

Fig.3 DMPO spin-trapping RSR under different temperature

\section{Conclusion}

The Fenton process conditions were investigated under thermal-assistance. The optimal conditions are $6 \mathrm{~g} / \mathrm{L}$ of $\mathrm{H}_{2} \mathrm{O}_{2}, 0.4 \mathrm{~g} / \mathrm{L}$ of $\mathrm{Fe}^{2+}$ and $\mathrm{pH}=3$ at $50^{\circ} \mathrm{C}$. Under optimal experimental conditions, the removal ratios of fluorescent Red $\mathrm{FB}$, clear Blue RR and clear Green 5B are 77.2, 93.5 and 86.8\% in $30 \mathrm{~min}$, respectively. It will be a highly efficient and convenient method for eliminating dye pollutants.

\section{Acknowledgement}

This research is supported by the Nature Science Foundation of Hubei Province (2014CFC1097) and Huangzhou Scholar Foundation (HZXZ-005).

\section{References}

[1] C. C. Su, M. Pukdee-Asa, C. Ratanatamskul, M. C. Lu, Desalination, 278 (2011) 211-218.

[2] S. Meric, D. Kaptan, T. Olmez, Chemosphere 54 (2004) 435-441.

[3] S. Sahinkaya, Journal of Industrial and Engineering Chemistry, 19 (2013) 601-605.

[4] S. Q. Liu, B. Xiao, L. R. Feng, S. S. Zhou, CARBON, 64 (2013) 197-206.

[5] A. N. Soon, B. H. Hameed, Desalination, 269 (2011) 1-16. 
[6] E. J. Ruiz, C. Arias, E. Brillas, Chemosphere, 82 (2011) 495-501.

[7] N. Ertugay, F. N. Acar, Arabian Journal of Chemistry, 2 (2013) 9-15.

[8] T. H. Kin, C. H. Park, J. M. Yang, S. Y. Kim, J. Hazard. Mater. B, 112 (2004) 95-103.

[9] S. Meric, H. Selcuk, V. Belgiorno, Water Res. 39 (2005) 1147-1153.

[10] R. Mecozzi, L. D. Palma, P. D. Filippis, Chemosphere, 71 (2008) 843-852.

[11] J. Blanco, F. Torrades, M. Moron, Chemical Engineering Journal, 240 (2014) 469-475.

[12] H. Cheng, S. Chou, S. S. Chen, C. Yu, Journal of Environmental Sciences, 26 (2014) 1307-1312.

[13] I. M. Kolthof, E. B. Sandell, E. J. Meehan, S. Buckstein, Quantitative chemical analysis, $4^{\text {th }}$ edition Macmillan, New York, 1969 1862-1867.

[14] A. P.H. A., Standard Methods for the Examination of Water and Wastewater, 19thed American Public Health Association, Washington, D. C., USA, 1998.

[15] H. B. Hu, L. W. Zhang, S. C. Zhang, J. Phys. Chem. B, 110 (2006) 3061-3065.

[16] D. Zhao, C. C. Chen, C. L. Yu, J. Phys. Chem. C, 113 (2009) 1360-13165. 